\title{
Seasonal Changes in the Ovary of the Immature Hake, Merlucius merluccius $L$.
}

\author{
$\mathrm{By}$ \\ C. F. Hickling, M.A. \\ Fisheries Laboratory, Lowestoft.
}

With 5 Figures in the Text.

THE major seasonal changes in the weight and " condition " of the somatic tissues of mature fish are attributable to spawning; they take the form of a seasonal cycle, in which, starting from a point of optimum condition, there is a progressive loss of condition due to the transference of material from the somatic tissues to the ripening gonads, followed by a recovery to the optimum condition after the spawning act is completed and while the gonads remain quiescent, or slowly begin to recover.

In at least four species of fish, namely, Cod, Haddock, Hake and Pilchard, the seasonal changes of condition in the somatic tissues found in the adult fish are foreshadowed in the immature fish, in which the gonad does not yet annually produce a large crop of eggs or spermatozoa, and in which therefore there is no apparent call by the gonad on the reserves. of the fish. Graham (1923) using data published by Russell (1922) demonstrates this phenomenon in the Cod, and Russell's data on the Haddock (1914) show the fish of $25 \mathrm{~cm}$., which consist mainly of immatures, show a loss of condition at the season when adult fish are losing condition during the ripening of the gonads. Ramalho (1932) shows that Pilchards of $13 \mathrm{~cm}$. show the same seasonal changes in condition as the adults, and I have shown (1930) that the seasonal changes in the condition of the somatic tissues of immature and adolescent female hake, which do not spawn, foreshadow closely the metabolic rhythm of adult hake.

Now the gonad also of the adolescent female hake shows seasonal changes very closely foreshadowing those of the mature female, and in the present paper a seasonal rhythm of activity, resembling that which occurs in the gonad of mature and adolescent hake, will be suggested for undoubtedly immature female hake.

It has not been possible to work with immature male hake also, for the male matures as early as the 20-24-cm. length group, and hake of this length are rarely and irregularly taken in the nets of commercial steamtrawlers. The female hake, on the other hand, does not become adolescent 
until at least $50 \mathrm{~cm}$. in length, and is not mature until $70 \mathrm{~cm}$. (Hickling, 1930 ; Birtwistle and Lewis, 1925) so that the collection of material for an investigation of the gonads of immature female hake has been an easy matter.

\section{A. The Material.}

The material and observations have been collected at sea, mainly during my voyages on hake research aboard steam-trawlers fishing for hake to the south and west of Ireland, but also during the annual surveys carried out in August, 1930, and August, 1931, in the Ministry of Agriculture and Fisheries' research vessel, George Bligh. There is available a series of samples of undoubtedly immature hake ovaries collected as follows :-

\section{Vessel.}

1. Lowther, Fleetwood

2. Sasebo, Cardiff

3. George Bligh

4. Tenedos, Milford

5. Trawler Prince, Milford

\section{Tenedos, Milford}

7 .

,', ,

8. Redgauntlet, Fleetwood June, 1931

9. George Bligh

10.

11 .

\section{Lily Macrae, Milford}

13. $E$ and $F$, Milford
Date.

March, 1930

May, 1930

August, 1930

October, 1930

December, 1930

January, 1931

April, 1931

August, 1931

,

,

November, 1931

February, 1932
Region.

West of Scotland.

West of Ireland.

South of Ireland.

South of Ireland.

South of Ireland.

South and west of Ireland. South and west of Ireland.

West of Ireland.

South of Ireland

(Labadie Bank).

West of Ireland

(Galway Bay).

North-west of Ireland

(Black Rock).

South of Ireland.

South and west of Ireland.

Each of these thirteen samples consists of fifteen ovaries, namely, five ovaries of hake of 35-39 cm., five of hake of 45-49 cm., and five of hake of $55-59 \mathrm{~cm}$. The ovaries were fixed in Bouin's fluid, and later were cut into sections and stained with iron hæmotoxylin and eosin at the Lowestoft Laboratory by Mr. B. G. Clarke, Chief Laboratory Assistant, to whom here I would express my thanks.

In addition to these samples of ovaries, during the cruises when samples $3,6,7,8,9,10,11$ and 12 were collected, a large number of determinations of the volume of immature hake ovaries were carried out. The determination was made simply by observing the displacement of water in 
a measuring cylinder. The results are given in Table IV at the end of this paper.

\section{B. Cytological Changes in the Ovaries of Immature Hake.}

The nuclear changes accompanying the development of the egg in the hake will now be briefly described, with the help of Wilson's authoritative text-book (1925).

Oogonial divisions have not been seen in any of the sections examined, and all oogonial divisions have been completed by the time the hake has attained a length of 35-39 cm., when about four years old. A few ovaries of hake of $25-29 \mathrm{~cm}$., which are approximately three years old (Hickling, 1933), were also examined, and in them also there was no sign of oogonial divisions. But such ovaries were full of " nests " of oocytes, showing that oogonial division had only recently been completed. It can safely be said that oogonial division is completed, in the hake, by the fourth year of life (when three years old), and the young ovary then contains only vast numbers of oocytes.

[In order to avoid confusion in this paper, the term oogonia is taken to refer, as Wilson himself implies in his Figure 135, to germ-cells still capable of division to form new germ-cells like themselves; the end products of oogonial divisions no longer divide, but are the starting point of oocyte growth or maturation, and are better themselves referred to as oocytes. This term should, in my opinion, also include those cells, sistercells of the oocytes, which form the accessory or follicle-cells in older ovaries, and which, in Wheeler's view (1924) are capable of metamorphosis back into oocytes and are thus potential oocytes.]

The oocytes observed in my sections are in the "resting" or net-like stage (Figure 1, A A). They are minute, and present in vast numbers just beneath the surface of the ovigerous lamellæ. No cytoplasm can be seen, the chromosomes are thin and stain only palely with iron hæmatoxylin, and there are several strongly basophilic nucleoli, of which one may ke more conspicuous than the others.

In the first stage of maturation, there is a single deeply-staining nucleolus, and the chromosomes appear more strongly basophilic and somewhat thicker and so more conspicuous (Figure 1, B B). The cytoplasm becomes visible as a very thin envelope around the nucleus. I shall refer to this stage of development as that of the "pre-synaptic egg " : they are easily visible in sections on account of their conspicuous nucleolus. The change to the pre-synaptic egg is accompanied by a considerable increase in size; it should be mentioned that, in Figure 1, the drawings of oocytes (A A) are on a larger scale than those of the presynaptic and later stages. 
This pre-synaptic stage leads on to synapsis (Figure 1, C). The large nucleolus lies to one side of the nucleus (which cannot be clearly differentiated from the cytoplasm) and the chromosomes appear as a bunch of thick, very deeply staining threads. My sections were not designed to. give minute cytological detail, so I cannot say how many chromosomes appear, and whether or at what stage they become ranged in pairs. The:

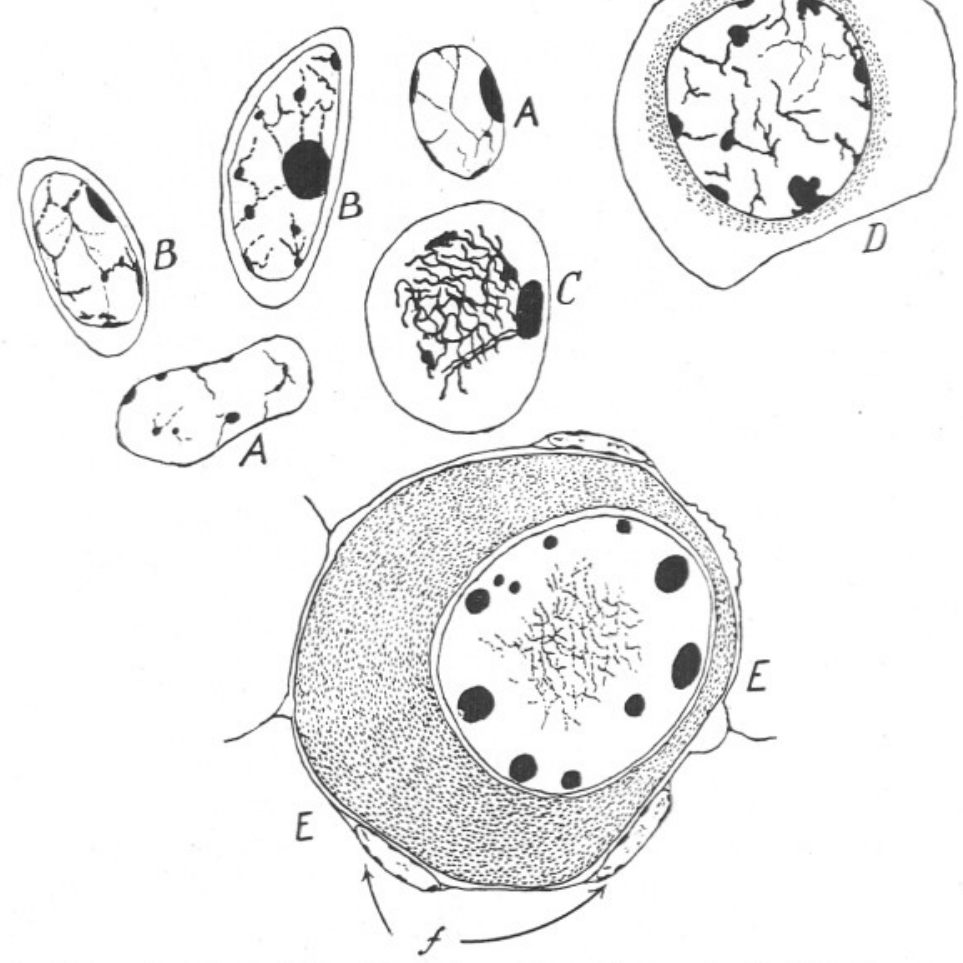

FIG. 1.-Successive stages in the change from the resting oocyte (A A) to the young egg.

(E). A A on larger scale than rest of drawings : explanation in text, Section B. (f. Follicle nuclei).

chromosomes, however, appear to be definitely polarized. Nuclei in synapsis are easily recognisable in sections, even under relatively low magnification.

The next stage (Figure 1, D) is accompanied by an enlargement of the nucleus; the chromosomes stain less deeply and separate, and a number of deeply staining nucleoli appear. The cytoplasm increases greatly in relative volume, and a ring of deeply staining matter appears in the cytoplasm about the nucleus. Here again my material does not allow me to. say anything definite about the origins of the cytoplasmic changes in the. egg. 
Finally (Figure 1, E) the nucleus becomes still more enlarged, the chromosomes lie loosely in the centre of the nucleus, staining so palely as to be barely visible, while the nucleoli increase in size and number and arrange themselves at the periphery of the nucleus. From this point onward the nucleus remains quiescent, while it is the turn of the cytoplasm to show a series of changes. Eggs in which the nucleus has reached the stage shown in Figure 1, E, are termed " post-synaptic eggs," or " young eggs."

Eggs in the stage shown in Figure 1, D, have been regarded, some as synaptic, others as post-synaptic eggs. It will be obvious that no hard and fast line can be drawn between stages which in reality pass smoothly from one to the other; the classifications adopted in this paper are necessarily arbitrary.

It has already been said that, from the stage shown in Figure 1, E, the nucleus remains quiescent while the cytoplasm shows a series of changes. First the cytoplasm becomes densely basophilic throughout, except for a thin clear zone immediately outside the nuclear membrane. It also rapidly increases in volume, and the follicle now becomes apparent. In Figure 1, E, three follicle nuclei may be seen in contact with the developing egg $(\mathrm{F})$. Next, the volume of the egg steadily increasing, a ring of oil globules appears in the cytoplasm near the nucleus. Daring the preparation and staining of sections this is dissolved away and is then manifested only as a reticulation of the cytoplasm. Finally, yolk granules appear, the follicular epithelium becomes fully developed, and the whole egg becomes opaque. The formation of yolk granules in a considerable number of the eggs in an ovary, or even of oil droplets in a large proportion of them, changes the naked-eye appearance of the ovary from a clear pale yellow to a turbid yellow, or a turbid yellowish red flecked with pink dots; an ovary having this appearance is no longer classed as immature and so passes out of the scope of this paper. Ovaries in these later stages have been fully dealt with elsewhere (1930). We are now concerned only with ovaries containing oocytes, and eggs in the pre-synaptic, synaptic and early post-synaptic stages; ovaries which are, by their naked-eye appearance, classed as immature.

\section{Seasonal Changes in the Occurrence of Synapsis.}

Synapsis is clearly an important phase in the development of the egg, namely, the passing over from the quiescent oocyte stage to the young egg stage. It marks the addition of new young eggs to the general eggstock in the ovary.

Now the cytoplasmic changes occurring in the eggs contained in the ovary of a mature hake are definitely seasonal (Hickling, 1930) and are manifested in the conspicuous changes described as the spawning-cycle. 
But the nuclear changes undergone in synapsis are a necessary preliminary to the cytoplasmic changes which are later initiated. It will be our present object to find whether these nuclear changes also show a seasonal cycle of activity.

It has already been said, in Section $A$, that a series of samples of immature hake ovaries were collected at different seasons of the year, each sample consisting of fifteen ovaries, namely, five each of hake of $35-39,45-49$ and $55-59 \mathrm{~cm}$. respectively. Sections of these ovaries were examined for nuclear activity in two distinct ways.

The first method was to make a traverse of each section, along its greatest diameter, under $\frac{1}{6} "$ objective, by means of a mechanical stage, and to count the number of nuclei in synapsis encountered in the field of view during the traverse. This might be expected to give a good estimate as to the extent to which synapsis is occurring in each ovary, provided that the nuclei in synapsis are fairly evenly distributed throughout the ovary, and also that all ovaries from fish of the same length-groups have roughly the same diameter. But the diameter of sections of ovaries of fish of the same length-group in the same sample varies considerably. Moreover, as the ovary enlarges with the growth of the fish, the ovigerous lamellæ become bigger, and therefore the young eggs, which lie immediately beneath the surface of these lamellæ, become irregularly scattered. A traverse of a section of the ovary from a fish of one of the larger lengthgroups is therefore not satisfactory as a method of assessing the relative amount of synapsis occurring. However, the rough estimate of the absolute numbers of nuclei in synapsis obtained by this method is a check on the results of the second method.

The second method was to classify an unselected sample of about 400 nuclei in each section into the three classes, "pre-synaptic," "synaptic " and "post-synaptic," or about 60,000 nuclei in all. No attempt was made to count the immense numbers of minute resting oocytes, and the nuclei were classified according to the definitions given in Section B. This method gives the percentage frequency of each class of nucleus in the unselected sample. It has the advantage over the first method of being independent of the diameter of the ovary, and of giving a more standardised estimate, but the disadvantage of giving relative frequencies only. Thus, if the percentage frequency of nuclei in synapsis is found to decrease in the summer months, as compared with the winter months, it does not necessarily follow that the process of synapsis is then less active. A simultaneous progressive increase in the percentage frequency of the other two classes of nucleus might equally well account for such a decrease.

Personal bias was guarded against in all cases by the replacement of the label bearing the date of collection by one bearing a serial number.

The results of the first method are given in Table I. The samples were 
examined in two batches, the first including those collected from March, 1930, to January, 1931. Further samples were then collected, from April, 1931, to February, 1932. It will be noticed, in Table I, that the average number of nuclei in synapsis per sample is much greater in the second than in the first batch, especially among the large fish of 45-49 and $55-59 \mathrm{~cm}$. This is probably because, with greater experience, the

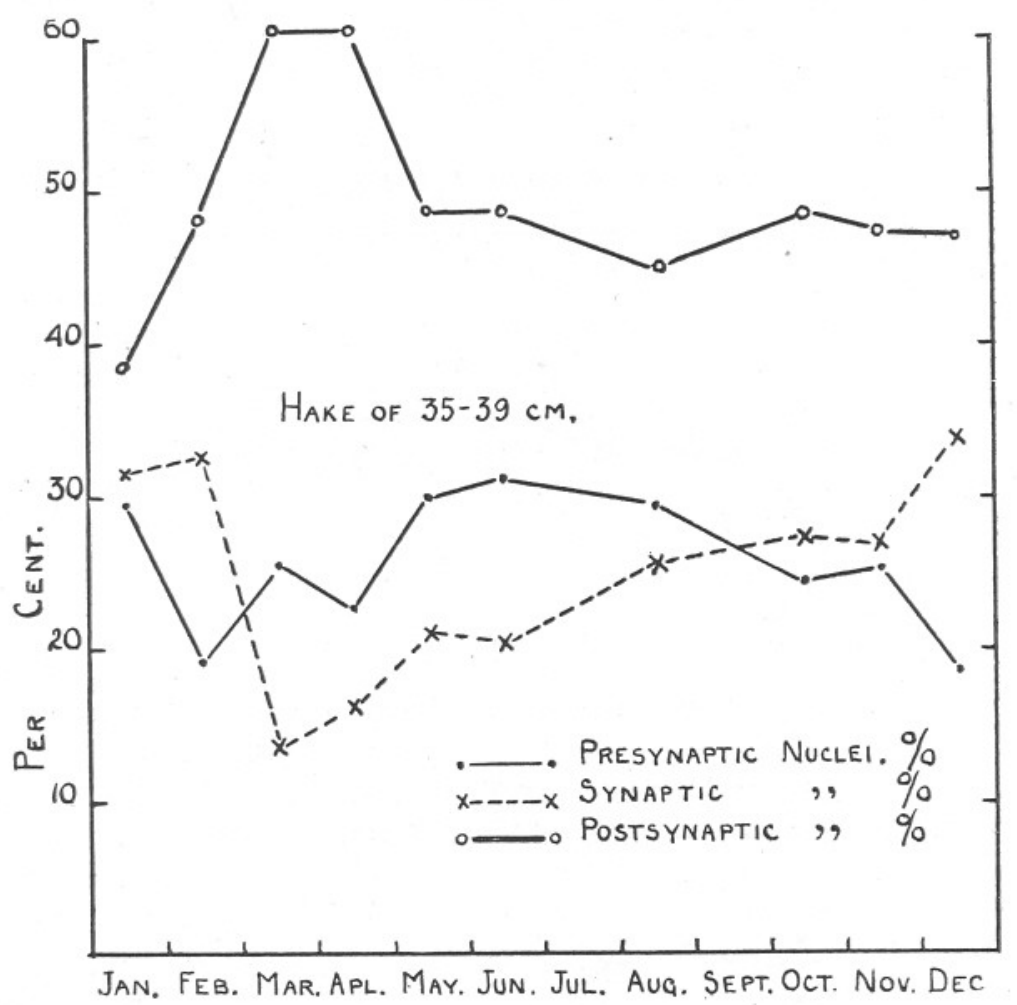

FIG. 2.-Seasonal change in the percentage frequency of nuclei in the three stages, in immature hake of $35-39 \mathrm{~cm}$. Data in Table I.

nuclei were classified with greater confidence. In spite of this discrepancy, however, I have included the original figures in Table I.

The results of the second method of examination are given in Table II. The samples were examined all together when the collection was complete. The results are much more consistent than those derived from the first method, and will be considered first. These are shown graphically in Figures 2 and 3. The consistency between all samples is such that the results from 1930, 1931 and 1932 can be grouped together as though they had all been collected in successive months in one calendar year, and they 


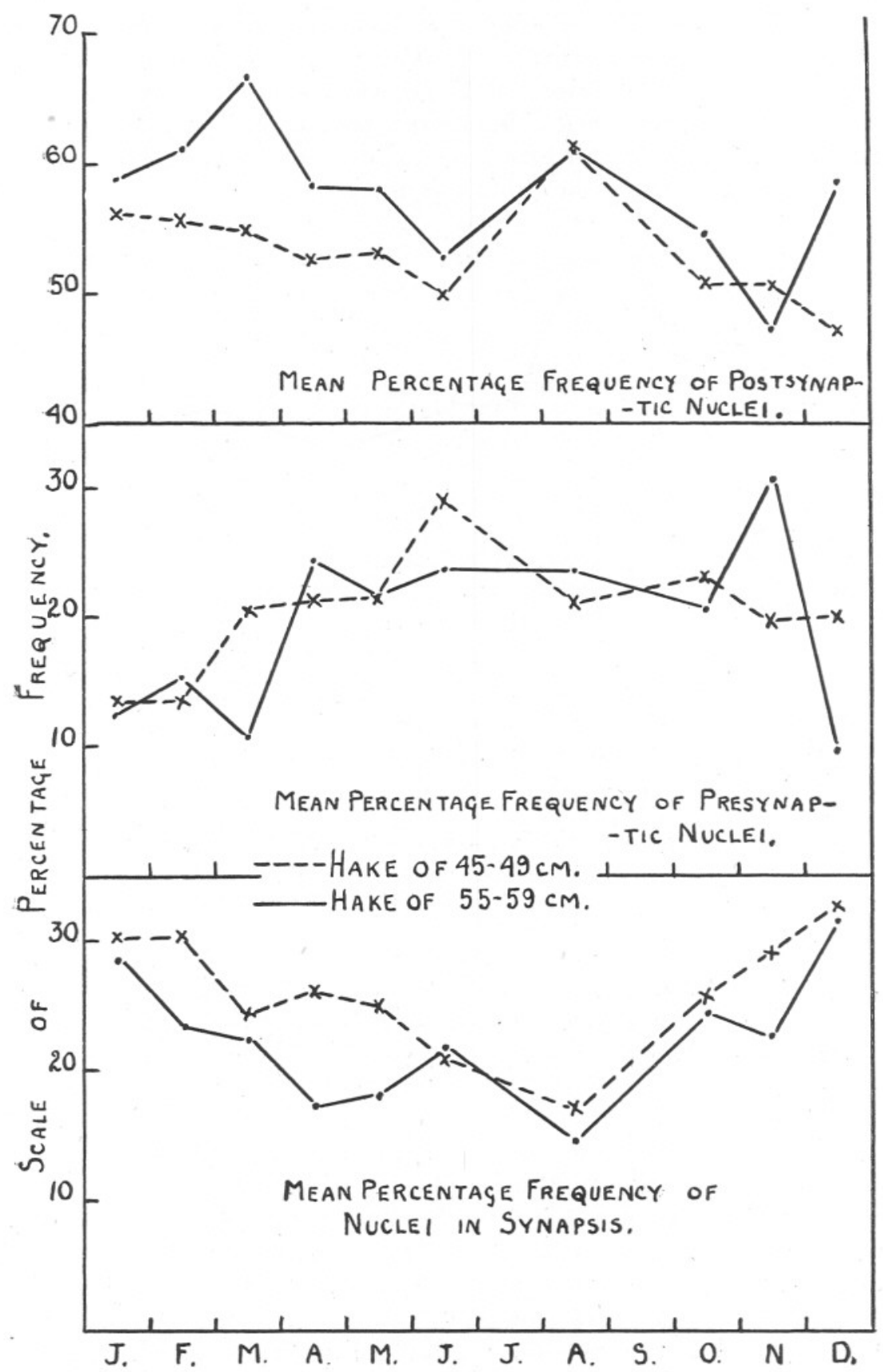

FIc. 3.-Seasonal change in the percentage frequency of nuclei in the three stages, in immature hake of $45-49$ and $55-59 \mathrm{~cm}$. Data in Table I. 
are so represented in Figures 2 and 3. The mean of the four August samples is taken as the figure for August.

In Figure 2 are plotted the points representing the mean percentage frequency of pre-synaptic, synaptic and post-synaptic nuclei in ovaries of hake of $35-39 \mathrm{~cm}$. in the samples.

The plotted points are joined by straight lines.

Nuclei in synapsis show a minimum percentage frequency in March, followed by a regular rise to a maximum in December. In January and February the percentage frequency remains high, and then there is a sharp drop to the minimum in March. Pre-synaptic nuclei have their minimum percentage frequency in February, and show an increase until June, when they decline again to a low value in December The percentage frequency of pre-synaptic nuclei drops from June until December as the percentage of synaptic nuclei rises, as indeed might be expected, since the presynaptic stage leads directly on to synapsis. The high value for pre-synaptic nuclei in the January sample is, however, anomalous in this respect.

Post-synaptic nuclei increase in percentage frequency from January to March and April, decline in May and remain steady for the rest of the year. Since the high values for post-synaptic nuclei follow immediately after the highest values for synaptic nuclei, it is probable that these high values also actually mark the addition of new post-synaptic eggs to the general stock of such in the young ovary. The later decline in the percentage frequency of post-synaptic nuclei, however, is probably due to the increase in the combined frequencies of pre-synaptic and synaptic nuclei.

In Figure 3 the seasonal changes in the precentage frequency of nuclei in each stage in the ovaries of hake of 45-49 and 55-59 cm. are shown; in order to avoid crowding the diagram the graphs for each class of nucleus are drawn separately.

The seasonal changes in the percentage frequency of nuclei in the synaptic stage agree sufficiently well for both length-groups to be represented in the same diagram. The correlation coefficient between the changes in hake of $45-49$ and $55-59 \mathrm{~cm}$. is $0 \cdot 68$, an agreement which would be obtained by chance in uncorrelated data only once in a hundred trials with the number of observations available (Fisher, 1930).

Nuclei in synapsis, in hake of $45-49$ and $55-59 \mathrm{~cm}$., form the greatest percentage of the nuclei in December, January and February (as in hake of $35-39 \mathrm{~cm}$.). The percentage frequency then declines to a minimum value in August (instead of in March, as in hake of 35-39 cm.) after which it rises again to the high winter values. Pre-synaptic nuclei have low values in January and February, but from March to June the percentage frequency rises. From June to September (disregarding the high value 
in hake of $55-59 \mathrm{~cm}$. in November) the percentage frequency of presynaptic nuclei declines somewhat. This agrees with the behaviour of pre-synaptic nuclei in hake of 35-39 $\mathrm{cm}$. Post-synaptic nuclei have high values from December to March (in fish of 55-59 cm.) and from January to, say, March (in fish of $45-49 \mathrm{~cm}$.) and then decline throughout the year except for a high value in both cases in August.

In all classes of immature female hake, nuclei in synapsis, while present in the ovary throughout the year, have a definite seasonal cycle of relative abundance, being relatively most abundant in the winter months of December, January and February. Hake of 35-39 $\mathrm{cm}$. differ from hake of $45-49$ and $55-59 \mathrm{~cm}$. in showing a minimum relative abundance in March, immediately following the time of maximum relative abundance, whereas the latter show a time of minimum relative abundance in August. These findings should now be compared with the results of the first method of examining the material, namely by the counts of the actual numbers of nuclei in synapsis observed during a traverse along the longest diameter of each ovary-section. The average numbers of nuclei in synapsis in the ovaries of hake of each length-group in each sample are given in Table I.

In hake of $35-39 \mathrm{~cm}$. the numbers of nuclei in synapsis increase from 13 per ovary-section in March, 1930, to a maximum of 83 per ovarysection in January 1931. There is then a sharp drop to 28 per ovarysection in April, 1931, followed again by an increase to a fresh maximum in November, 1931, and February, 1932. (The average of the three samples collected in August, 1931, is here considered.) Clearly, as far as hake of $35-39 \mathrm{~cm}$. are concerned, both the relative and the absolute numbers of nuclei in synapsis are greatest in the winter months, and fall to the minimum in March and April.

In hake of $45-49$ and of $55-59 \mathrm{~cm}$. the changes in the average numbers of nuclei per ovary-section from sample to sample are very similar to one another. In the first batch of readings the average number of nuclei in synapsis rises from March to May, 1930, then falls to August and October, 1930, rises again sharply to December, 1930, and falls in January, 1931. In the second batch of readings a more definite trend is shown by the samples. The average number of nuclei in synapsis falls from April, 1931, to August, 1931, and rises again to high values in November, 1931, and February, 1932. The second series of readings, in ovaries of hake of 45-49 and 55-59 cm., shows the same seasonal trend in the absolute numbers of nuclei in synapsis as in their relative numbers (Table II), though the first series does not.

In my view, therefore, there is reason for believing that the important process of synapsis, which marks the change from the quiescent oocyte to the young egg, is most active in the winter months. The data in 
Table II and in Figures 2 and 3 also suggest that the process is initiated in the period January to June by the appearance of pre-synaptic nuclei, presumably by metamorphosis of a certain proportion of the resting oocytes. The pre-synaptic nuclei pass over into synapsis, which reaches its maximum activity in the months from December to January. Synapsis leads to the formation of post-synaptic eggs, or young eggs, which accordingly show their greatest relative abundance from January to April.

\section{Seasonal Changes in the Mean Diameter of the Eggs.}

In Section $\mathrm{C}$ evidence was shown that, as the result of a seasonal cycle in the intensity of the process of synapsis, there is a seasonal change in the rate of addition of new young eggs to the general egg-stock contained in the ovary, the addition of new young eggs being most active in the months from January to April. This addition of new young eggs might be expected to lower the average diameter of the stock of post-synaptic eggs in the ovary, thus bringing about a seasonal variation in the average diameter. Accordingly, a large number of unselected eggs were measured along their longest diameter, in the same sections of ovaries as were used, in Section C, for an estimation of the occurrence of synapsis. For each

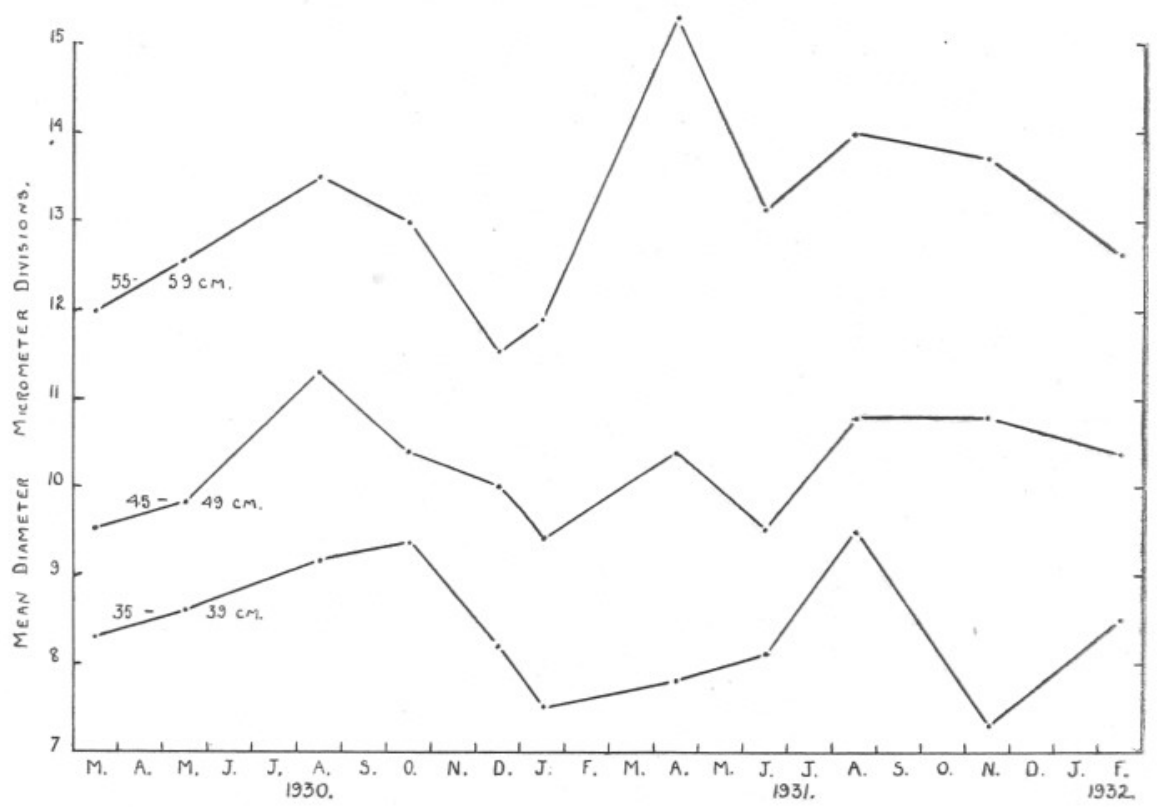

FIG. 4.-Seasonal changes in the mean diameter of the ovarian eggs in immature hake of $35-39,45-49$, and $55-59 \mathrm{~cm}$. Data in Table II. 
length-group within each sample the mean diameter of the eggs was calculated, and these are given in Table III. They are shown graphically in Figure 4. Since the samples collected in 1931 give results differing from those collected in 1930, in Figure 4 the results are given in the order of collection of the samples.

In all three length-groups, the mean egg-diameter is low in March, 1930, and then rises to a maximum in early autumn. From this maximum the mean diameter decreases to a minimum in midwinter. From this winter minimum the mean diameter rises to a maximum in April, 1932 (55$59 \mathrm{~cm}$.), or August, 1932 (35-39 and 45-49 cm.), and then declines again. The cycle of changes in 1931 are irregular as compared with 1930 especially in hake of $45-49 \mathrm{~cm}$., but they can still be recognised. It appears that there is a seasonal fluctuation in the mean diameter of the eggs in the ovaries of immature hake, such that the mean diameter is higher in the summer months than in the winter months. Taking the months from October to March as representing the winter months, and from April to August as representing the summer months, there is an increase in mean volume of the egg (calculated from the mean diameter) in the summer over the winter months of 28 per cent in hake of $35-39 \mathrm{~cm}$., of 12 per cent in hake of 45-49 cm., and of 38 per cent in hake of $55-59 \mathrm{~cm}$.

There is a close correspondence between the seasonal changes in the mean diameter of the eggs in the immature and the mature ovary. In Figure 4 it has been shown that the mean diameter of the eggs in the immature ovary tends to be greater in the months from April to August than in the months from September to March. The mature ovary has a low mean weight in the months from October to March, a high mean weight in the months from April to July; the maximum mean weight is found in July (Hickling, 1930). But the changes in mean weight of the mature ovary are due to the growth of the current season's crop of ripening eggs, which undergo an immense increase in diameter and volume. In the immature ovary this growth in the diameter of the eggs carries them, in the larger immature ovaries, to the point of incipient formation of oil in the cytoplasm. Further than this they cannot go, for where a large number of the eggs enlarge and secrete oil, and still more, yolk, the naked-eye appearance of the ovary changes, and it becomes by definition adolescent or mature.

A correlation can be shown between the mean volume of the eggs contained in the immature ovary (calculated from the mean diameter D by the approximation, Volume $=\frac{D^{3}}{2}$ ) and the mean volume of the ovary.

In Table IV are given the mean volumes of the ovaries of immature hake of 35-39 and 45-49 cm., as determined by displacement, during certain of the voyages in which samples of ovaries were obtained. In- 
sufficient numbers of immature hake of $55-59 \mathrm{~cm}$. were available to obtain reliable mean volumes of the ovaries of this length-group also.

In hake of $35-39 \mathrm{~cm}$., the correlation coefficient between the mean volume of the egg and the mean volume of the ovary is 0.81 ; a correlation as good as this would be obtained by chance in uncorrelated material between once and twice in a hundred trials (Fisher, 1930). In hake of $45-49 \mathrm{~cm}$. the correlation coefficient is $0 \cdot 76$; a correlation as good as this would be obtained about twice in a hundred trials by chance in uncorrelated material. Changes in the mean volume of the eggs therefore cause changes in the mean volume of the ovary, which therefore, in immature hake, tends to be slightly larger, relatively to the fish, in summer than in winter.

\section{E. DISCUSSION.}

Seasonal changes can be demonstrated in the ovaries of undoubtedly immature female hake. The nuclear changes undergone in synapsis, during which the quiescent oocyte metamorphoses into the young egg, while occurring throughout the year, reach a maximum in the winter months (December, January, and February). The addition thereby of a new batch of young eggs to the stock of eggs already accumulated in the ovary lowers the mean diameter of the eggs in this stock; with the slackening off of synapsis during the summer the mean diameter of the eggs in the immature ovary increases as the new eggs grow up into the general egg-stock. The increase in mean diameter of the eggs causes an increase in the mean volume of the whole ovary, which is greater, relatively to the length of the fish, in summer than in winter.

These seasonal changes in the ovaries of immature hake foreshadow those which have been found to occur in the ovaries of mature hake. In mature fish also there is an addition, in the winter months, of a new batch of young eggs to the reserve stock in the ovary (Hickling, 1930), and in them also there is in summer an increase in the mean diameter of the eggs as a quota of the reserve fund of eggs undergoes an immense increase in diameter and volume during maturation. In mature fish these eggs are ripening for spawning in the early summer months. [In my previous paper I could detect no seasonal variation in the mean weight of the ovaries of immature hake, but such seasonal variations as I have shown in the present paper would affect the mean weight of the immature ovary only to a trifling degree, well within the experimental error of weighing carried out at sea with a spring-balance.]

Such a foreshadowing, in the immature ovary, of the seasonal changes occurring in the mature ovary has been recorded in a freshwater Cottus (Cottus bairdii Girard) by Hann (1927). This is a small fish with a short 
life-history, the female maturing at the end of its second year of life. But the ovarian cycle can be detected in the first year of life, while the fish is definitely immature.

The conclusions reached in this paper, in conjunction with those reached in my previous papers on the seasonal changes in the ovaries of adolescent and mature hake, and on the growth-rate (1933), may be used to present an account of the later ovarian development of this fish.

By the end of the third year of life at latest, when the fish is $25-29 \mathrm{~cm}$. in length, the division of the oogonia has been completed, and the ovary is full of resting oocytes, of which, even at this stage, many have metamorphosed into young eggs. In each subsequent winter, a fresh batch of resting oocytes becomes active, undergoes synapsis, and in the following summer grows into the " stock" of eggs in the ovary. In each subsequent summer also a few of the eggs may show incipient development, leading to an increase in size and to the appearance of oil globules in the cytoplasm. By the seventh year of life, when the fish is about $55-59 \mathrm{~cm}$. in length, this incipient cytoplasmic development takes place on a considerable scale, and at 65-69 $\mathrm{cm}$. (Table $\mathrm{V}$ and Figure 4, in my 1930 paper) when in its eighth year of life, this enlargement of a portion of the reserve fund eggs, with the secretion of oil, and even of yolk, changes the nakedeye appearance of the ovary, which is now classed as adolescent. Adolescent ovaries show a seasonal fluctuation in weight such that this is high from April to August, and low from October to March. But adolescent ovaries do not produce ripe eggs, and the advanced eggs are re-absorbed at the close of the season of adolescence. Finally, at about 75-79 $\mathrm{cm}$., when in its ninth or tenth year of life, the enlargement of a portion of the eggs, and the secretion in them of oil and yolk, leads to the complete development of the eggs and so to spawning, which occurs mainly in the months from April to July.

If the results set out in this paper are accepted, clearly the seasonal rhythm of activity in the ovary of the hake, which in the mature fish is manifested as the spawning cycle, is already established at an early stage in the life-history of the fish, many years before maturity is attained. I have already shown (1930) that a seasonal rhythm of activity in the somatic tissues of the hake is present in immature fish. In Figure 5 are shown (continuous lines) the graphs for the quarterly changes in mean volume of the eggs in the ovaries of immature hake of 35-39, 45-49, and $55-59 \mathrm{~cm}$. (the data in Table II having been recalculated as quarterly averages, and the volume calculated from the approximation Volume $=$ $\left.\frac{\text { Diameter }^{3}}{2}\right)$. The broken line shows the quarterly changes in mean weight of the liver of inmature female hake of $50-59 \mathrm{~cm}$. (recalculated from the data in Table VIa, 1930). The mean volume of the eggs increases from 
the first to the third quarters of the year, and then declines in the fourth quarter of the year. The mean weight of the liver decreases from the first to the third quarters of the year and recovers sharply in the fourth quarter of the year. In a mature fish these changes would be interpreted as indicating a transference of material from the liver (somatic tissue) to the gonad. No such suggestion need be made with regard to immature fish; the graphs simply show that seasonal rythms are present in both

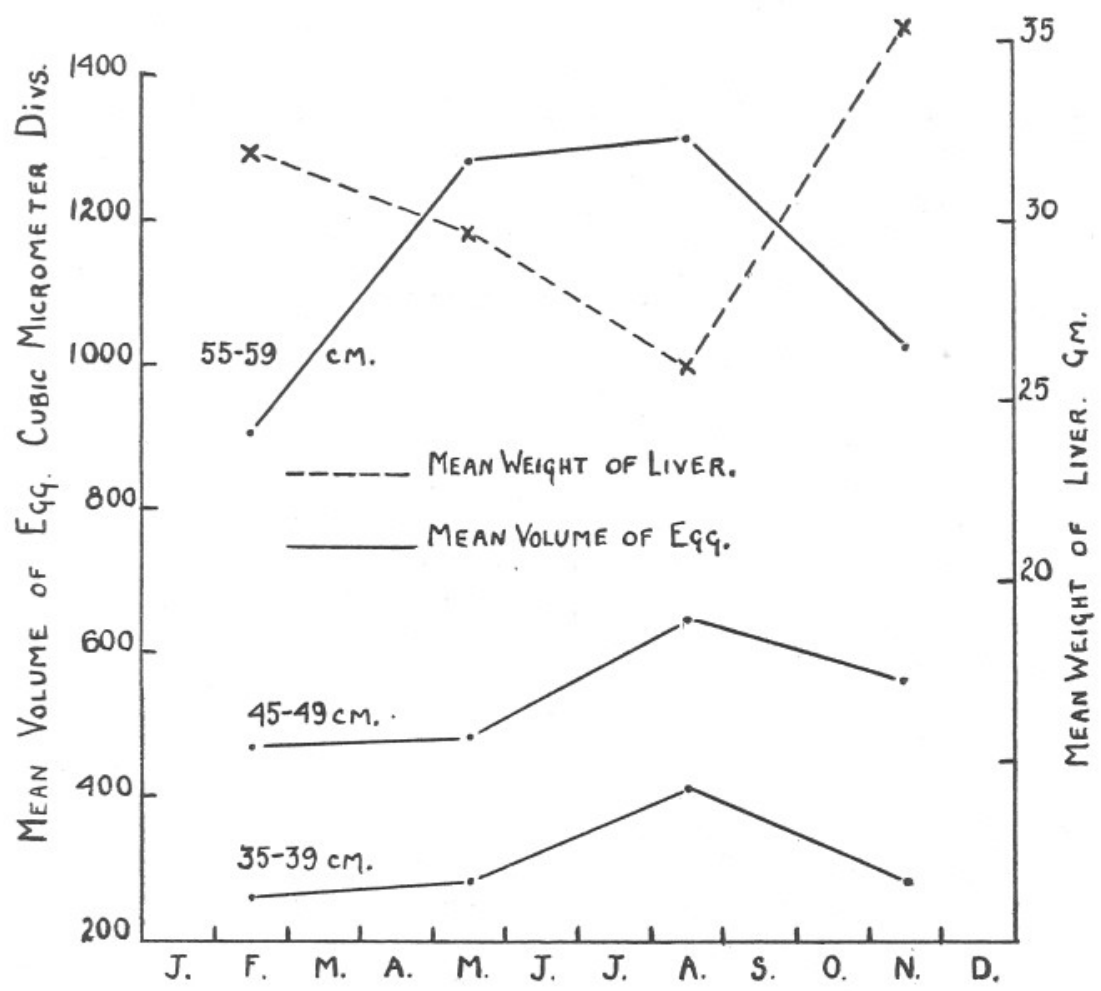

FIG. 5.-Quarterly changes in the mean volume of the ovarian egg in immature hake, calculated from Table II. Also quarterly changes in the mean weight of the liver in immature hake of 50-59 cm., calculated from data in Hickling, 1930.

somatic tissues and gonad which closely resemble those occurring in mature fish (Figures 1, 11, 17, Hickling, 1930).

An interesting point that arises is in connexion with the formation of " growth-rings" in the skeletal structures of fishes, which are so widely used in age-estimation. Graham $(1928$, ii) found, as a result of a study of the literature, that in no species of fish has a satisfactory relation been shown between the conditions in the external environment and the modification in the growth of the skeletal structures which manifests 
itself as a growth-ring. He was inclined to think that growth-rate in the cod (which is intimately related with the width of the sclerites in the scale, and so with the manner of growth of the scale) is an "inherent rythmical response," that is, due to an internal factor (Graham, 1928, i). As early as 1907 Dahl had implied an internal rather than an external factor, as connected with the formation of growth-rings in the herring, by his use of the term "physiological winter." But he rejected the possibility that the spawning process could have any connexion with ring-formation because the growth-rings are found to be as well formed in immature as in mature herrings. Schneider (1910) while attacking Dahl's hypothesis, really takes much the same view-point, but suggests that a physiological rhythm may be already present in the immature fish. In my 1933 paper I showed that a growthring is formed in the otolith of the hake at the time of greatest exhaustion after spawning, i.e. about October in the mature fish. Immature hake (see Figure 5 in this paper) show the same exhaustion, though they do not spawn. The picture may now be completed by this demonstration, that the physiological rhythm in both gonad and somatic tissues of mature hake are already detectable in immature hake. If the hake is typical of teleosts generally, the fact that immature fish show the same growthrings as the adult need not in future preclude any hypothesis suggesting that the discontinuous growth of the skeletal structures is associated with the physiological stresses of the spawning cycle.

\section{SUMMARY.}

A seasonal variation is found in the ovaries of immature hake (Merlucius merluccius L.).

There appears to be a seasonal change in the rate at which young eggs are formed from resting oocytes, as indicated (1) by the change in the relative abundance of nuclei in synapsis, and (2) by the change in the average diameter of the eggs in the egg-stock in the ovary. These processes show considerable correspondence in their season of incidence with the ovarian cycle of the mature and adolescent fish.

A physiological rhythm has now been detected in both somatic tissues and gonad in the immature hake, which foreshadows the physiological rhythm associated with the spawning cycle in the mature hake. The implication of this on the question of the formation of " growth-rings" in the skeletal structures is briefly discussed. 


\section{LITERATURE CONSULTED.}

Birtwistle, W., and Lewis, H. M. 1924. Hake Investigations. Rep. Lancs. Sea-Fish. Lab., 1924, Liverpool, 1925.

DAHL, K. 1907. The Scales of the Herring. Rep. Norwegian Fish. Invest., II, 6, Bergen, 1907.

Fisher, R. A. 1930. Statistical methods for research workers. 3rd Ed., Oliver and Boyd, London, 1930.

Graham, M. 1924. The Annual cycle in the life of Mature Cod in the North Sea. Fish. Invest. Ser. II, Vol. VI, 6. Ministry of Agriculture and Fisheries, London, 1924.

1928 (i). Studies of age-determination in Fish. Part I. A study of the growth-rate of Codling, etc. Ibid., Ser. II, Vol. XI, 2, 1928.

1928 (ii). Studies of age-determination in Fish. Part II. A Survey of the Literature. Ibid., Ser. II, Vol. XI, 3, 1928.

Hann, H. W. 1927. The Germ-cells of Cottus bairdii. Journ. Morph. and Physiol., Philadelphia, Vol. 43.

Hickling, C. F. 1930. The Natural History of the Hake. Part III. Seasonal Changes in the condition of the Hake. Fish. Invest., Ser. II, Vol. XII, No. 1, 1930, Ministry of Agriculture and Fisheries, London, 1930 .

— 1933. The Natural History of the Hake. Part IV. AgeDetermination and the Growth-Rate. Ibid., XIII, No. 2, 1933.

Ramalho, A. 1932. Fluctuation Saisonnière du poids moyen de la Sardine. C.R. Soc. Biol. Paris, Vol. CXIII, No. 23, pp. 754-756.

Russell, E. S. 1914. Report on market measurements in relation to the English Haddock Fishery. Fish. Invest. Ser. II, Vol. I, Ministry of Agriculture and Fisheries, London, 1914.

- 1922. Market Measurements in relation to the English Cod Fishery. Ibid., Vol. V, No. 1, London, 1922.

SchneIder, G. 1910. Über die Altersbestimmung bei Heringen nach den Zuwachszonen der Schuppen. Ur Svenska Hydrografiskbiologiska Komm. Skrifter, Stockholm, 1910.

Wheeler, J. F. G. 1924. The Growth of the Egg in the Dab. Quart. Journal Microscopical Science, Vol. 68, N.S., No. 272, London, November, 1924.

Wilson, E. B. 1925. The Cell in Development and Heredity. 3rd Edition. The Macmillan Company, New York, 1925. 
TABLE I.

Average Number of Nuclei in Synapsis encountered during Two Traverse of the Ovary-Sections.

Samples.

Hake of $35-39 \mathrm{~cm}$.

Hake of $55-59 \mathrm{~cm}$
Hake of $45-49 \mathrm{~cm}$.

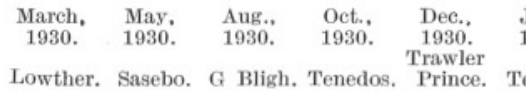

$\begin{array}{llllll}\text { Jan., April, June, Aug., Aug., Aug., Nov., } & \text { Feb., } \\ 1931 & 1931 & \text { 1931. } & 1932 .\end{array}$ Red- G. Bligh G. Bligh G. Bligh Tily E. and F. nedos. Tenedos. gauntlet. (Labadie (Galway (Black Macrae

88

$\begin{array}{rrrrrrrrrrrrr}13 & 28 & 41 & 44 & 53 & 83 & 28 & 67 & 115 & 53 & 51 & 96 & 88 \\ 26 & 36 & 17 & 10 & 47 & 22 & 82 & 65 & 36 & 32 & 16 & 65 & 64 \\ 10 & 29 & 26 & 16 & 28 & 20 & 55 & 53 & 32 & 40 & 40 & 100 & 80\end{array}$

TABLE II

Mean Percentage Frequency of the three Nuclear Stages defined in Section B.

Hake of $35-39 \mathrm{~cm}$

\begin{tabular}{|c|c|c|c|c|c|c|c|c|c|c|c|c|c|c|}
\hline \multirow{3}{*}{$\begin{array}{l}\text { Mean Percentage } \\
\text { Frequency of Nuclei in } \\
\text { Stages }\end{array}$} & Pre-synaptic & $25 \cdot 7$ & $30 \cdot 0$ & $29 \cdot 9$ & $24 \cdot 2$ & $18 \cdot 9$ & $29 \cdot 6$ & $22 \cdot 7$ & $31 \cdot 4$ & $29 \cdot 1$ & $25 \cdot 8$ & $34 \cdot 3$ & $25 \cdot 4$ & $19 \cdot 2$ \\
\hline & Synaptic & $13 \cdot 8$ & $21 \cdot 2$ & $24 \cdot 1$ & $27 \cdot 2$ & $34 \cdot 2$ & $31 \cdot 7$ & $16 \cdot 7$ & $20 \cdot 4$ & $27 \cdot 7$ & $25 \cdot 5$ & $27 \cdot 1$ & $27 \cdot 2$ & $32 \cdot 7$ \\
\hline & Post-synaptic & $60 \cdot 5$ & $48 \cdot 8$ & $46 \cdot 0$ & $48 \cdot 6$ & $47 \cdot 0$ & $38 \cdot 7$ & $60 \cdot 6$ & $48 \cdot 2$ & $43 \cdot 2$ & $48 \cdot 7$ & $38 \cdot 6$ & $47 \cdot 3$ & $48 \cdot 1$ \\
\hline \multirow{3}{*}{$\begin{array}{l}\text { Hake of } 45-49 \mathrm{~cm} . \\
\text { Mean Percentage } \\
\text { Frequency of Nuclei in } \\
\quad \text { Stages }\end{array}$} & Pre-synaptic & $20 \cdot 7$ & $21 \cdot 6$ & $22 \cdot 9$ & $23 \cdot 2$ & $20 \cdot 0$ & $13 \cdot 5$ & $21 \cdot 4$ & $29 \cdot 1$ & $23 \cdot 5$ & $16 \cdot 6$ & $22 \cdot 0$ & $19 \cdot 9$ & $13 \cdot 8$ \\
\hline & Synaptic & $24 \cdot 4$ & $25 \cdot 2$ & $17 \cdot 5$ & $25 \cdot \overline{9}$ & $32 \cdot 8$ & $30 \cdot 2$ & $26 \cdot 2$ & $21 \cdot 0$ & $22 \cdot 9$ & $12 \cdot 0$ & $16 \cdot 2$ & $29 \cdot 3$ & $30 \cdot 4$ \\
\hline & Post-synaptic & $54 \cdot 9$ & $53 \cdot 2$ & $59 \cdot 6$ & $50 \cdot 7$ & $47 \cdot 1$ & $56 \cdot 3$ & $52 \cdot 5$ & $49 \cdot 8$ & $53 \cdot 6$ & $71 \cdot 4$ & $61 \cdot 7$ & $50 \cdot 8$ & $55 \cdot 8$ \\
\hline \multirow{3}{*}{$\begin{array}{l}\text { Hake of } 55-59 \mathrm{~cm} . \\
\text { Mean Percentage } \\
\text { Frequency of Nuclei in } \\
\quad \text { Stages }\end{array}$} & Pre-synaptic & $10 \cdot 7$ & $21 \cdot 7$ & $23 \cdot 8$ & $20 \cdot 6$ & $9 \cdot 9$ & $12 \cdot 6$ & $24 \cdot 4$ & $23 \cdot 4$ & $23 \cdot 8$ & $26 \cdot 2$ & $20 \cdot 9$ & $30 \cdot 4$ & $15 \cdot 4$ \\
\hline & Synaptic & $22 \cdot 4$ & $18 \cdot 3$ & $17 \cdot 2$ & $24 \cdot 3$ & $31 \cdot 6$ & $28 \cdot 5$ & $17 \cdot 2$ & $21 \cdot 9$ & $12 \cdot 5$ & $18 \cdot 7$ & $10 \cdot 3$ & $22 \cdot 5$ & $23 \cdot 4$ \\
\hline & Post-synaptic & $66 \cdot 9$ & $58 \cdot 2$ & $58 \cdot \overline{9}$ & $54 \cdot 6$ & $58 \cdot 5$ & $58 \cdot 9$ & $58 \cdot 4$ & $52 \cdot 6$ & $63 \cdot 7$ & $55 \cdot 1$ & $68 \cdot 7$ & $47 \cdot 1$ & $61 \cdot 2$ \\
\hline
\end{tabular}


TABLE III.

Means of the mean Diameters of unselected Samples of Eggs measured in each Ovary (micrometer DIVISIONS $)(10$ DIV. $=37 \mu)$.

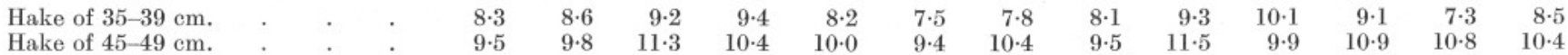

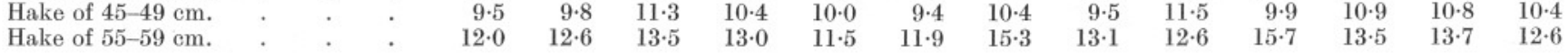

\section{TABLE IV.}

Mean Volume of Immature Hake Ovaries, determined by Displacement (cubic centimetres).

In hake of $35-39 \mathrm{~cm}$.

(No. of Observations)

In hake of $45-49 \mathrm{~cm}$.

(No. of Observations)

$$
\begin{gathered}
1 \cdot 18 \\
20 \\
3 \cdot 11
\end{gathered}
$$

18

$\begin{array}{ccccccc}0 \cdot 71 & 0 \cdot 76 & 0 \cdot 82 & 0 \cdot 80 & 0 \cdot 86 & 1 \cdot 09 & 0 \cdot 86 \\ 20 & 16 & 20 & 22 & 32 & 14 & 15 \\ 2 \cdot 53 & 2 \cdot 54 & 3 \cdot 02 & 2 \cdot 03 & 2 \cdot 17 & 2 \cdot 97 & 2 \cdot 11 \\ 17 & 16 & 20 & 20 & 16 & 14 & 15\end{array}$


Erratum in M. V. Lebour's paper on "Balcis":

Page 68, third column, line 36. For "pernula" read "trifasciata". 